\title{
Preoperative, Multidisciplinary Clinical Optimization of Patients with Severely Depressed Left Ventricular Ejection Fraction Who Are Undergoing Coronary Artery Bypass Grafting
}

\author{
Islam Mohammad Shehata - Tiffany D. Odell • Amir Elhassan • \\ Maxim Spektor · Ivan Urits · Omar Viswanath • George M. Jeha • \\ Elyse M. Cornett · Alan D. Kaye
}

Received: September 8, 2020 / Published online: December 23, 2020

(C) The Author(s) 2020

\section{ABSTRACT}

Coronary artery bypass grafting (CABG) remains a routine operation despite major advancements in angioplastic procedures. Around 200,000 CABG procedures are performed annually in the U.S. Patients who are not candidates for angioplasty intervention often have advanced coronary disease and comorbidities

I. M. Shehata

Department of Anesthesiology, Faculty of Medicine, Ain Shams University, Cairo, Egypt

T. D. Odell

Department of Neurosurgery, Desert Regional

Medical Center, Palm Springs, CA, USA

A. Elhassan

Department of Anesthesiology, Desert Regional

Medical Center, Palm Springs, CA, USA

M. Spektor

Department of Surgery, Desert Regional Medical

Center, Palm Springs, CA, USA

I. Urits

Department of Anesthesiology, Critical Care, and Pain Medicine, Harvard Medical School, Beth Israel Deaconess Medical Center, Boston, MA, USA

I. Urits · O. Viswanath · E. M. Cornett .

A. D. Kaye $(\square)$

Department of Anesthesiology, LSU Health

Shreveport, Shreveport, LA, USA

e-mail: akaye@lsuhsc.edu that raise the risk of heart failure with decreased ejection fraction to around $25 \%$. Over the years, significant developments in various preoperative interventions have occurred; in this paper, we suggest a multidisciplinary preoperative algorithm that can be included in a regularly scheduled multidisciplinary care plan.
O. Viswanath

Department of Anesthesiology, University of Arizona College of Medicine, Phoenix, Phoenix, AZ, USA

O. Viswanath

Department of Anesthesiology, Creighton University School of Medicine, Omaha, NE, USA

O. Viswanath

Valley Anesthesiology and Pain Consultants, Envision Physician Services, Phoenix, AZ, USA

\section{G. M. Jeha}

Louisiana State University Health Sciences Center, New Orleans, LA, USA 
Keywords: Cardiomyopathy; Coronary artery bypass; Low ejection fraction; Preoperative optimization

\section{Key Summary Points}

Evolving studies in recent years have better defined the role of risk stratification, pharmacologic and assist device support, and increased adverse outcomes in emergency CABG.

Patients who are not candidates for angioplastic intervention often have advanced coronary disease and comorbidities increasing the likelihood of encountering heart failure with reduced ejection fraction up to about $25 \%$.

Ideally, in the near future, we will be in a position to create a consensus-driven algorithm which will include the most manipulable factors to enhance postoperative outcomes.

Questions remain with regard to the role of preoperative transfusion and ideal hemoglobin levels, and which medications should be utilized which would directly improve outcomes.

\section{DIGITAL FEATURES}

This article is published with digital features to facilitate understanding of the article. You can access the digital features on the article's associated Figshare page. To view digital features for this article go to https://doi.org/10.6084/m9. figshare.13277126.

\section{INTRODUCTION}

Many surgical subspecialties, often in partnership with anesthesiology, have looked at preoperative factors that could be optimized to improve postoperative outcomes. The first published reports many decades ago involved beta-blockers and delaying elective surgery after acute myocardial infarction.

Coronary artery bypass grafting (CABG) has become a common operation worldwide. Despite the consensus on the surgical technique, outcomes vary for a multitude of reasons. In this regard, a retrospective cohort study that included 40,083 consecutive patients who underwent CABG from 2008 to 2015 showed that 10,284 patients $(25.7 \%)$ had reduced ejection fraction (EF) and 4816 patients $(12.0 \%)$ had heart failure with reduced ejection fraction (HFrEF). The study revealed a higher adjusted mortality risk in patients with HFrEF than in those with preserved EF [1].

To date, there have never been clearly defined and agreed upon preoperative multidisciplinary pathways for patients with a higher risk of mortality who require CABG. This is surprising given the abundance of clinical research which has included preoperative pathways to optimize patients at higher risk in many other surgical fields. Therefore, the following focused review looks at factors and considerations, given this significant need, to create an algorithm utilizing multidisciplinary interventions for patients with a higher risk of mortality to ensure the best possible clinical outcome (Fig. 1).

This article is based on previously conducted studies and does not contain any new studies with human participants or animals performed by any of the authors.

\section{PREVIOUS OUTCOMES OF CABG}

Data analysis for 55,515 patients who underwent CABG from a New York state database between 1997 and $1999 \quad(20.5 \%$ with EF $31-40 \%, 10.4 \%$ with EF $21-30 \%$, and $4.4 \%$ with $\mathrm{EF}<20 \%$ ) showed an increase in multi-organ dysfunction in the low-EF group. However, it also depicted significant benefit with regard to improved postoperative EF, increased long-term survival, improvement in New York Heart Association (NYHA) classification, and higher quality of life [2]. 
Another cohort study from 2002 to 2007 included 1212 patients with EF of 35\% that demonstrated a lower mortality rate over ten years among patients who underwent CABG and received medical treatment compared to those who received medical therapy alone [3].

A meta-analysis of the related articles until 2016 was conducted to compare medical therapy and revascularization strategies (CABG and percutaneous coronary intervention [PCI]). The meta-analysis revealed significant survival benefits from the CABG compared with $\mathrm{PCI}$ in patients with HFrEF [4].

\section{PREOPERATIVE MANAGEMENT}

\section{Clinical Pathway}

A longitudinal quasi-experimental pre-test/post-test study was conducted to compare the clinical outcome between implementing the pathway and the conventional care for 256 patients admitted for CABG between 2004 to 2006 [5]. The findings were in favor of traditional care concerning health-related quality of life. However, improvement of the learning curve and a limitation of inappropriate randomization indicated the need for further research to evaluate the proposed clinical pathway's efficacy.

Our preoperative pathway implementation goal is to standardize HFrEF patients' management in a multidisciplinary fashion that allows for controlled individualization and can be used as a starting point to create a more robust, universally standardized guideline in the future.

The pathway includes the multidisciplinary team (MDT) members, interventions, and the implementation of interventions to correct reversible risk factors and optimize cardiac performance in patients using prophylactic mechanical or pharmacological supportive therapy.

\section{The Role of Multidisciplinary Teams (MDT)}

A randomized trial of 200 hospitalized patients diagnosed with chronic heart failure demonstrated the efficacy of a multidisciplinary care model to improve outcomes at a comparable cost [6].

MDT is not a novel concept; it refers to members of different professional specialties who work together effectively to benefit the patients. MDT success necessitates clarity of roles, good communication, and institutional support [7]. Cardiac surgical MDT may include intensive care physicians, cardiology physicians, cardiac surgeons, anesthesiologists, rehabilitation physicians, nutritionists, and nurses. The role of this MDT is to optimize the risk factors and discuss the prophylactic indication for preoperative pharmacological or mechanical supportive therapy.

The cardiology physician's role includes adjustment of the medical therapy established for HFrEF such as angiotensin-converting enzyme inhibitors (ACEIs), angiotensin receptor blockers (ARBs), beta-blockers, aldosterone antagonists, and hydralazine-isosorbide and dinitrate.

This high-risk category of patients necessitates an experienced cardiothoracic surgeon who can decrease the duration of the aortic cross-clamp and perform either on-pump arrested or beating heart and off-pump surgery. Standard on-pump CABG is associated with higher mortality in these high-risk patients, especially in emergency CABG [8].

The nutritionist's role is to assess the nutritional state in these high-risk patients and treat malnutrition to achieve a goal albumin level of at least $30 \mathrm{~g} / \mathrm{L}$ and a body mass index of $>20$ [9]. A prospective, single-center exploratory clinical pilot study involving 22 frail patients undergoing CABG suggested that providing a home-based rehabilitation program may reduce hospital length of stay. Therefore, the physiotherapist should be included in the MDT to optimize the preoperative nutritional status and then follow the patients in their home [10]. 


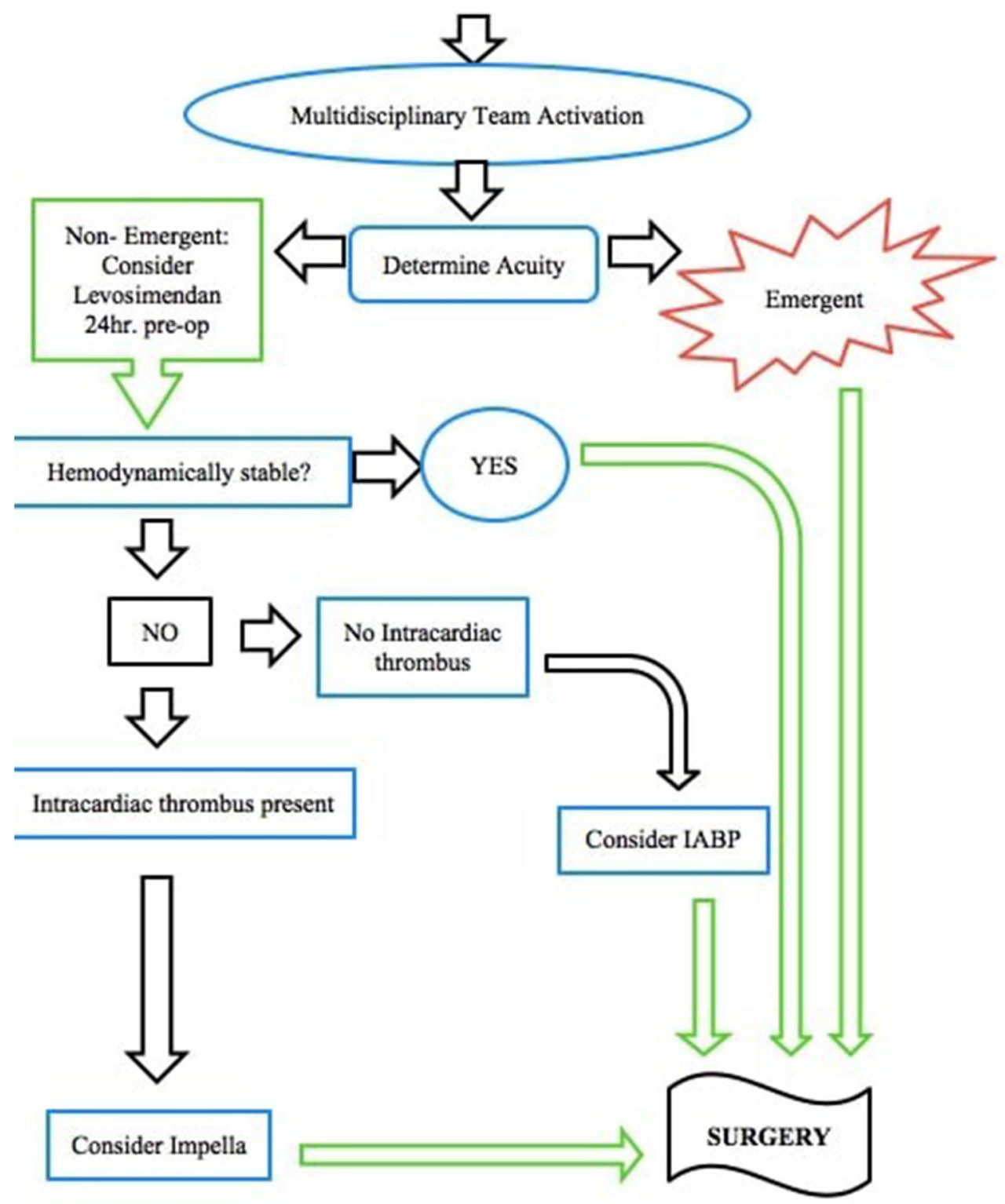

Fig. 1 Schematic representing a multidisciplinary preoperative algorithm that can be included in a regularly scheduled multidisciplinary care plan

\section{Predictors of Mortality and Morbidity}

A cohort study involving 379 patients with left ventricular ejection fraction $(\mathrm{LVEF}) \leq 35 \%$ who underwent CABG between 1995 and 1999 was conducted to assess the preoperative risk factors [11]. The study identified two significant predictors of mortality: an estimated glomerular filtration rate (eGFR) of $<45 \mathrm{~mL} / \mathrm{min} / 1.73 \mathrm{~m} 2$ and patients with a median age of 76 years compared with their younger cohort. In another study, 201 patients with LVEF of $\leq 25 \%$ who underwent CABG between January 2012 and March 2017 were retrospectively reviewed to identify preoperative risk factors related to increased length of hospital stay or operative mortality [12]. The study demonstrated that a more extended length of hospital 
stay was associated with the absence of preoperative beta-blockers, low preoperative albumin levels $(<3.5 \mathrm{~g} / \mathrm{dl})$, and higher Society of Thoracic Surgeons Predicted Risk of Mortality score. A systematic review of six observational studies with a combined total of $1,231,850$ patients was performed to investigate the role of beta-blocker use before CABG. The study showed no notable reduction in mortality or incidence of major postoperative complications such as myocardial infarction or atrial fibrillation [13]. Moreover, those patients with reduced EF who are not on preoperative beta-blockers may not tolerate initiation of beta-blockers secondary to hypotension or decreased cardiac output. The Society of Thoracic Surgeons Predicted Risk of Mortality score is an excellent predictor of 30-day mortality after cardiac surgery and longterm survival as well [14].

\section{Preoperative Anemia}

The World Health Organization had defined anemia as hemoglobin levels below $13 \mathrm{~g} / \mathrm{dl}$ in men and $12 \mathrm{~g} / \mathrm{dl}$ in women [15]. Anemia is classified according to the hemoglobin level into mild (women 10-12 gm/dl and men 10-13 $\mathrm{gm} / \mathrm{dl}$ ) or severe form (both sexes, hemoglobin $<10 \mathrm{gm} / \mathrm{dl})$.

Preoperative anemia is a common comorbidity which may affect up to half of patients undergoing cardiac surgery [16]. This high incidence is associated with increased intraoperative blood transfusion requirements, postoperative acute kidney injury, and higher mortality $[17,18]$.

Iron-deficiency anemia is a common etiology treated with oral or intravenous iron supplementation in mild cases. However, there is no valid association between iron administration and decreased blood transfusion requirements [19]. Moreover, the optimal time to start the preoperative administration is unclear and not applicable in emergencies. Patients with noniron-deficiency anemia may benefit from erythropoietin administration to reduce the need for postoperative blood transfusion. In 320 patients undergoing off-pump CABG surgery, administration of erythropoietin 2 days before and 2 days after surgery was associated with a lower rate of blood transfusion in the postoperative period [20]. The combination of erythropoietin and iron supplementation may greatly benefit severe anemia, especially in patients who refuse a blood transfusion, such as the Jehovah's Witnesses population.

Preoperative red blood cell transfusion should not be routinely recommended in preoperatively anemic patients (class of recommendation III, level of evidence C) [21]. However, preoperative red blood cell transfusion should be implemented in cases of emergency surgery and life-threatening anemia.

\section{Preoperative Intervention}

\section{Prophylactic Mechanical Support}

Mechanical circulatory support (MCS) is no longer reserved for patients with severe hemodynamic instability as a bridge for a heart transplant. MCS is now approved for prophylactic use in cardiac surgery to improve outcomes [22].

\section{Intra-Aortic Balloon Pump (IABP)}

Since 2011, the American College of Cardiology/American Heart Association has recommended preoperative IABP insertion to decrease the mortality rate in high-risk CABG patients with $\mathrm{EF}$ of $<30 \%$ [23].

More than 400 physicians from 52 countries investigated all studies published in peer-reviewed journals that discussed nonsurgical interventions with a statistically significant effect on mortality in the setting of cardiac surgery. The authors selected prophylactic IABP as among the ten techniques that reduced mortality, and recommended direct future research in that field [24].

Another prospective, single-center, randomized controlled trial, which included 232 patients, demonstrated decreased mortality in off-pump CABG [25].

Additionally, a single-center prospective randomized controlled trial enrolled 110 patients undergoing $\mathrm{CABG}$ with $\mathrm{EF}$ of $<35 \%$ to determine the outcome of preoperative IABP use. This study demonstrated no significant 
difference in outcome with prophylactic IABP. However, the patients selected in that study did not suffer from preoperative hemodynamic instability [26].

The less invasive nature of IABP as a means to increase cardiac output has made it a frequent choice for use as temporary mechanical circulatory support. Therefore, another role of MDT is to identify which patients should undergo IABP on an individual basis.

\section{Percutaneous Left Ventricular Assist Devices} Impella, the transvalvular aortic axial flow device, is one of the most widely used percutaneous left ventricular assist devices. Impella has been successfully employed for a variety of indications, including high-risk percutaneous coronary intervention (EF $<35 \%$ ), post-infarction cardiogenic shock, and fulminant myocarditis [27].

There is currently limited available evidence on the preoperative use of Impella. However, prophylactic use for patients with severely depressed EF during non-emergency high-risk PCI is approved to improve the outcome, as shown in the well-known PROTECT-II trial [28]. Extrapolating this data, the clinical situation of cardiogenic shock following myocardial infarction will necessitate bridging to CABG with Impella support. A registry analysis of the Society of Thoracic Surgeons Adult Cardiac Surgery Database for the preoperative use of MCS, including Impella, showed notable benefits for this high-risk patient population ( $\mathrm{EF}<25 \%$ in most of them) [29].

\section{Prophylactic Pharmacology Support}

\section{Levosimendan}

Levosimendan, a calcium sensitizer and adenosine triphosphate (ATP)-dependent potassium channel opener with favorable inotropic, vasodilatory, and cardioprotective properties, has been widely used in clinical practice and has also been well studied in clinical trials for stabilization of at-risk patients undergoing cardiac surgery.

The most recent meta-analysis on prophylactic use in cardiac surgery included 16 randomized trials, with 2273 patients. The study found no significant reduction in mortality at 30 days or beyond 30 days [30].

However, more than 40 clinical trials support levosimendan for its beneficial effects on multiple body systems. The three most recent randomized, placebo-controlled multicenter studies, i.e., LICORN, CHEETAH, and LEVOCTS, showed improvement of low cardiac output syndrome, renal-protective effects, shortening of intensive care length of stay, reduction of pulmonary artery pressure, decreased incidence of atrial fibrillation, and improvement of the EF [31].

Levosimendan initiation timing varies between $12 \mathrm{~h}$ pre-operative or $24 \mathrm{~h}$ post-induction. However, subgroup analyses suggest promising results in high-risk patients with severely depressed cardiac function $(\mathrm{EF}<35 \%)$ when the infusion of levosimendan was started $24 \mathrm{~h}$ before the surgery time [32, 33].

\section{Milrinone}

There is a lack of literature examining the preoperative use of milrinone, by either an intravenous or inhalation route, for patients who are scheduled to undergo CABG. The studies that discussed the preemptive intravenous use of milrinone concerned intraoperative administration before the bypass or after the aortic clamp release. The first study enrolled 70 patients with $\mathrm{EF}$ of $<35 \%$ who underwent on-pump CABG [34]. Results demonstrated a significant lowering of inotropic agent duration and reduction of myocardial infarction in the milrinone group. The second study, which included 45 CABG patients, showed attenuation of postoperative deterioration of ventricular function and reduced the necessary doses of dopamine and nitroglycerin [35].

However, a meta-analysis of randomized trials published at BioMed Central, PubMed, EMBASE, and the Cochrane Central Register of Clinical Trials showed no difference in cardiac surgery mortality between the milrinone group and the control group [36].

Moreover, milrinone has been demonstrated to be an independent risk factor for postoperative AF following elective cardiac surgery [37]. 


\section{Emergency $C A B G$}

Although emergency CABG accounts for a small percentage of all CABG surgeries, it has been associated with significantly increased adverse outcomes compared to non-emergency CABG. These adverse effects include higher in-hospital mortality, postoperative complications such as permanent neurological sequelae, and renal failure. The common indications of emergency CABG are ongoing ischemia, angiographic accident, or cardiogenic shock with PCI unsuitability (38).

Emergency CABG in such high-risk patients necessitates prompt management by the dedicated MDT. Therefore, the MDT should be available for such emergencies to decrease the door-to-heart time. Moreover, coding the patients may shorten the therapeutic delay, which should help to improve the outcome.

\section{CONCLUSION}

In recent years, evolving studies have better defined the role of risk stratification, pharmacologic and assist device support, and increased adverse outcomes in emergency CABG. Understanding the results of these studies and additional ones that are ongoing can serve as a template for perioperative management best practices for those patients undergoing CABG who are high risk. Without a doubt, this is an area that can ultimately benefit those patients who stand to have the highest risk of postoperative complications. Ideally, soon we will create a consensus-driven algorithm that will include the most manipulable factors to enhance postoperative outcomes. Questions remain regarding the role of preoperative transfusion and ideal hemoglobin levels and which medications should be utilized that would directly improve outcomes.

\section{ACKNOWLEDGEMENTS}

Funding. No funding or sponsorship was received for this study or publication of this article.
Authorship. All named authors meet the International Committee of Medical Journal Editors (ICMJE) criteria for authorship for this article, take responsibility for the integrity of the work as a whole, and have given their approval for this version to be published.

Disclosures. Islam Mohammad Shehata, Tiffany D. Odell, Amir Elhassan, Maxim Spektor, Ivan Urits, Omar Viswanath, George M. Jeha, Elyse M. Cornett, and Alan D. Kaye have nothing to disclose.

Compliance with Ethics Guidelines. This article is based on previously conducted studies and does not contain any new studies with human participants or animals performed by any of the authors.

Data Availability. Data sharing is not applicable to this article as no datasets were generated or analyzed during the current study.

Open Access. This article is licensed under a Creative Commons Attribution-NonCommercial 4.0 International License, which permits any non-commercial use, sharing, adaptation, distribution and reproduction in any medium or format, as long as you give appropriate credit to the original author(s) and the source, provide a link to the Creative Commons licence, and indicate if changes were made. The images or other third party material in this article are included in the article's Creative Commons licence, unless indicated otherwise in a credit line to the material. If material is not included in the article's Creative Commons licence and your intended use is not permitted by statutory regulation or exceeds the permitted use, you will need to obtain permission directly from the copyright holder. To view a copy of this licence, visit http://creativecommons.org/licenses/by$\mathrm{nc} / 4.0 /$.

\section{REFERENCES}

1. Sun LY, Tu JV, Bader Eddeen A, Liu PP. Prevalence and long-term survival after coronary artery bypass grafting in women and men with heart failure and 
preserved versus reduced ejection fraction. J Am Heart Assoc. 2018;7(12):e008902.

2. Topkara VK, Cheema FH, Kesavaramanujam S, Mercando ML, Cheema AF, Namerow PB, Argenziano M, Naka Y, Oz MC, Esrig BC. Coronary artery bypass grafting in patients with low ejection fraction. Circulation. 2005;112(9_supplement):I-344.

3. Velazquez EJ, Lee KL, Jones RH, Al-Khalidi HR, Hill JA, Panza JA, Michler RE, Bonow RO, Doenst T, Petrie MC, Oh JK. Coronary-artery bypass surgery in patients with ischemic cardiomyopathy. N Engl J Med. 2016 Apr 21;374(16):1511-20.

4. Wolff G, Dimitroulis D, Andreotti F, Kołodziejczak M, Jung C, Scicchitano P, Devito F, Zito A, Occhipinti M, Castiglioni B, Calveri G. Survival benefits of invasive versus conservative strategies in heart failure in patients with reduced ejection fraction and coronary artery disease: a meta-analysis. Circ Heart Fail. 2017;10(1):e003255.

5. El Baz N, Middel B, Van Dijk JP, Boonstra PW, Reijneveld SA. Coronary artery bypass graft (CABG) surgery patients in a clinical pathway gained less in health-related quality of life as compared with patients who undergo CABG in a conventional-care plan. J Eval Clin Pract. 2009 Jun;15(3):498-505.

6. Kasper EK, Gerstenblith G, Hefter G, Van Anden E, Brinker JA, Thiemann DR, Terrin M, Forman S, Gottlieb SH. A randomized trial of the efficacy of multidisciplinary care in heart failure outpatients at high risk of hospital readmission. J Am Coll Cardiol. 2002 Feb 6;39(3):471-80.

7. Wilson V, Pirie A. Multidisciplinary teamworking indicators of good practice. Edinburgh: Scottish Council for Research in Education; 2000 Sep.

8. Ferrari E, Stalder N, von Segesser LK. On-pump beating heart coronary surgery for high risk patients requiring emergency multiple coronary artery bypass grafting. J Cardiothorac Surg. 2008 Dec;3(1): 38.

9. Pichette M, Liszkowski M, Ducharme A. Preoperative optimization of the heart failure patient undergoing cardiac surgery. Can J Cardiol. 2017 Jan 1;33(1):72-9.

10. Waite I, Deshpande R, Baghai M, Massey T, Wendler $\mathrm{O}$, Greenwood S. Home-based preoperative rehabilitation (prehab) to improve physical function and reduce hospital length of stay for frail patients undergoing coronary artery bypass graft and valve surgery. J Cardiothorac Surg. 2017 Dec;12(1):91.

11. Hillis GS, Zehr KJ, Williams AW, Schaff HV, Orzulak TA, Daly RC, Mullany CJ, Rodeheffer RJ, Oh JK.
Outcome of patients with low ejection fraction undergoing coronary artery bypass grafting: renal function and mortality after 3.8 years. Circulation. 2006;114(1_supplement):I-414.

12. Yu PJ, Lin D, Catalano M, Cassiere H, Kohn N, Hartman A. Predictors of increased length of hospital stay in patients with severe cardiomyopathy undergoing coronary artery bypass grafting. J Cardiothorac Vasc Anesth. 2019;33(10):2703-8.

13. Wang L, Wang H, Hou X. Short-term effects of preoperative beta-blocker use for isolated coronary artery bypass grafting: a systematic review and meta-analysis. J Thorac Cardiovasc Surg. 2018 Feb $1 ; 155(2): 620-9$.

14. Puskas JD, Kilgo PD, Thourani VH, Lattouf OM, Chen E, Vega JD, Cooper W, Guyton RA, Halkos M. The Society of Thoracic Surgeons 30-day predicted risk of mortality score also predicts long-term survival. Ann Thorac Surg. 2012 Jan 1;93(1):26-35.

15. World Health Organization. Logic model for micronutrient interventions in public health: vitamin and mineral nutrition information system. Geneva: World Health Organization; 2016.

16. Loor G, Koch CG, Sabik JF, Li L, Blackstone EH. Implications and management of anemia in cardiac surgery: current state of knowledge. J Thorac Cardiovasc Surg (Print). 2012;144(3):538-46.

17. Von Heymann C, Kaufner L, Sander M, Spies C, Schmidt K, Gombotz H, Wernecke KD, Balzer F. Does the severity of preoperative anemia or blood transfusion have a stronger impact on long-term survival after cardiac surgery? J Thorac Cardiovasc Surg. 2016;152(5):1412-20.

18. Engoren M, Schwann TA, Habib RH, Neill SN, Vance JL, Likosky DS. The independent effects of anemia and transfusion on mortality after coronary artery bypass. Ann Thorac Surg. 2014 Feb 1;97(2): 514-20.

19. Hogan M, Klein AA, Richards T. The impact of anaemia and intravenous iron replacement therapy on outcomes in cardiac surgery. Eur J Cardiothorac Surg. 2015 Feb 1;47(2):218-26.

20. Weltert L, D'Alessandro S, Nardella S, Girola F, Bellisario A, Maselli D, De Paulis R. Preoperative very short-term, high-dose erythropoietin administration diminishes blood transfusion rate in offpump coronary artery bypass: a randomized blind controlled study. J Thorac Cardiovasc Surg. 2010;139(3):621-7.

21. Pagano D, Milojevic M, Meesters MI, Benedetto U, Bolliger D, von Heymann C, Jeppsson A, Koster A, Osnabrugge RL, Ranucci M, Ravn HB. 2017 EACTS/ 
EACTA Guidelines on patient blood management for adult cardiac surgery. Eur J Cardiothorac Surg. 2018;53(1):79-111.

22. Windecker S, Kolh P, Alfonso F, Collet JP, Cremer J. ESC/EACTS Guidelines on myocardial revascularization: web addenda. The Task Force on Myocardial Revascularization of the European Society of Cardiology (ESC) and the European Association for Cardio-Thoracic Surgery (EACTS). Developed with the special contribution of the European Association of Percutaneous Cardiovascular Interventions (EAPCI). Eur J Cardiothorac Surg. 2014;46(4): 517-92.

23. Hillis LD, Smith PK, Anderson JL, Bittl JA, Bridges CR, Byrne JG, Cigarroa JE, DiSesa VJ, Hiratzka LF, Hutter AM, Jessen ME. ACCF/AHA guideline for coronary artery bypass graft surgery: a report of the American College of Cardiology Foundation/ American Heart Association Task Force on Practice Guidelines developed in collaboration with the American Association for Thoracic Surgery, Society of Cardiovascular Anesthesiologists, and Society of Thoracic Surgeons. J Am Coll Cardiol. 2011;58(24): e123-210.

24. Landoni G, Lomivorotov V, Silvetti S, Neto CN, Pisano A, Alvaro G, Hajjar LA, Paternoster G, Riha H, Monaco F, Szekely A. Nonsurgical strategies to reduce mortality in patients undergoing cardiac surgery: an updated consensus process. J Cardiothorac Vasc Anesth. 2018;32(1):225-35.

25. Shi M, Huang J, Pang L, Wang Y. Preoperative insertion of an intra-aortic balloon pump improved the prognosis of high-risk patients undergoing offpump coronary artery bypass grafting. J Int Med Res. 2011;39(4):1163-8.

26. Ranucci M, Castelvecchio S, Biondi A, De Vincentiis C, Ballotta A, Varrica A, Frigiola A, Menicanti L. Surgical and Clinical Outcome Research (SCORE) Group. A randomized controlled trial of preoperative intra-aortic balloon pump in coronary patients with poor left ventricular function undergoing coronary artery bypass surgery. Crit Care Med. 2013;41(11):2476-83.

27. Burzotta F, Trani C, Doshi SN, Townend J, van Geuns RJ, Hunziker P, Schieffer B, Karatolios K, Møller JE, Ribichini FL, Schäfer A. Impella ventricular support in clinical practice: collaborative viewpoint from a European expert user group. Int J Cardiol. 2015;15(201):684-91.

28. O'Neill WW, Kleiman NS, Moses J, Henriques JP, Dixon S, Massaro J, Palacios I, Maini B, Mulukutla S, Džavík V, Popma J. A prospective, randomized clinical trial of hemodynamic support with Impella 2.5 versus intra-aortic balloon pump in patients undergoing high-risk percutaneous coronary intervention: the PROTECT II study. Circulation. 2012;126(14):1717-27.

29. Acharya D, Gulack BC, Loyaga-Rendon RY, Davies JE, He X, Brennan JM, Thourani VH, Williams ML. Clinical characteristics and outcomes of patients with myocardial infarction and cardiogenic shock undergoing coronary artery bypass surgery: data from the Society of Thoracic Surgeons national database. Ann Thorac Surg. 2016;101(2):558-66.

30. Elbadawi A, Elgendy IY, Saad M, Megaly M, Mentias A, Abuzaid AS, Shahin HI, Goswamy V, Abowali H, London B. Meta-analysis of trials on prophylactic use of levosimendan in patients undergoing cardiac surgery. Ann Thorac Surg. 2018;105(5):1403-10.

31. Guarracino F, Heringlake M, Cholley B, Bettex D, Bouchez S, Lomivorotov VV, Rajek A, Kivikko M, Pollesello P. Use of levosimendan in cardiac surgery: an update after the LEVO-CTS, CHEETAH, and LICORN trials in the light of clinical practice. J Cardiovasc Pharmacol. 2018;71(1):1.

32. Desai PM, Sarkar MS, Umbarkar SR. Prophylactic preoperative levosimendan for off-pump coronary artery bypass grafting in patients with left ventricular dysfunction: Single-centered randomized prospective study. Ann Cardiac Anaesth. 2018;21(2):123.

33. Wang W, Zhou X, Liao X, Liu B, Yu H. The efficacy and safety of prophylactic use of levosimendan on patients undergoing coronary artery bypass graft: a systematic review and meta-analysis. J Anesth. 2019;25:1-8.

34. Jebeli M, Ghazinoor M, Mandegar MH, Rasouli MR, Eghtesadi-Araghi P, Goodarzynejad H, Mohammadzadeh R, Darehzereshki A, Dianat S. Effect of milrinone on short-term outcome of patients with myocardial dysfunction undergoing coronary artery bypass graft: a randomized controlled trial. Cardiol J. 2010;17(1):73-8.

35. Kikura M, Sato S. The efficacy of preemptive milrinone or amrinone therapy in patients undergoing coronary artery bypass grafting. Anesth Analg. 2002;94(1):22-30.

36. Majure DT, Greco T, Greco M, Ponschab M, BiondiZoccai G, Zangrillo A, Landoni G. Meta-analysis of randomized trials of effect of milrinone on mortality in cardiac surgery: an update. J Cardiothorac Vasc Anesth. 2013;27(2):220-9.

37. Fleming GA, Murray KT, Yu C, Byrne JG, Greelish JP, Petracek MR, Hoff SJ, Ball SK, Brown NJ, Pretorius $\mathrm{M}$. Milrinone use is associated with postoperative atrial fibrillation following cardiac surgery. Circulation. 2008;118(16):1619. 
38. Schumer EM, Chaney JH, Trivedi JR, Linsky PL, Williams ML, Slaughter MS. Emergency coronary artery bypass grafting: indications and outcomes

from 2003 through 2013. Tex Heart Inst J. 2016;43(3):214-9. 